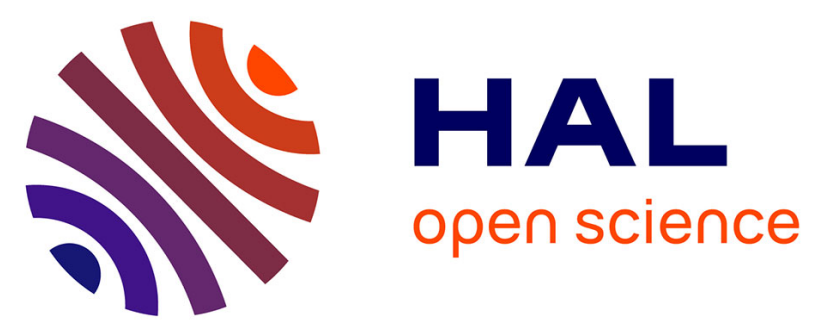

\title{
Influence of dissolved oxygen on the bioleaching efficiency under oxygen enriched atmosphere
}

Anne-Gwenaëlle Guezennec, Catherine Joulian, Jérome Jacob, Anas Archane, Dominique Ibarra, Raphaelle Gregory, Françoise Bodénan, Patrick d'Hugues

\section{- To cite this version:}

Anne-Gwenaëlle Guezennec, Catherine Joulian, Jérome Jacob, Anas Archane, Dominique Ibarra, et al. Influence of dissolved oxygen on the bioleaching efficiency under oxygen enriched atmosphere. Minerals Engineering, 2017, 10.1016/j.mineng.2016.10.016 . hal-01427774

\section{HAL Id: hal-01427774 https: / hal-brgm.archives-ouvertes.fr/hal-01427774}

Submitted on 6 Jan 2017

HAL is a multi-disciplinary open access archive for the deposit and dissemination of scientific research documents, whether they are published or not. The documents may come from teaching and research institutions in France or abroad, or from public or private research centers.
L'archive ouverte pluridisciplinaire HAL, est destinée au dépôt et à la diffusion de documents scientifiques de niveau recherche, publiés ou non, émanant des établissements d'enseignement et de recherche français ou étrangers, des laboratoires publics ou privés.

\section{(1) (1) $\$$}

Distributed under a Creative Commons Attribution - NonCommercial - NoDerivatives 44.0 


\title{
Influence of dissolved oxygen on the bioleaching efficiency under oxygen enriched atmosphere
}

\author{
Anne-Gwénaëlle Guezennec $^{1 *}$, C. Joulian' ${ }^{1}$, J. Jacob ${ }^{1}$, A. Archane ${ }^{2}$, D. Ibarra ${ }^{3}$, R. Gregory ${ }^{3}$, F. \\ Bodénan $^{1}$, P. d'Hugues $^{1}$ \\ ${ }^{1}$ BRGM -Water, Environment \& Ecotechnologies Division, 3, av. Claude Guillemin, BP 36009, 45060 \\ Orléans Cedex 2, France - +33 (0)2 386431 36, a.guezennec@brgm.fr \\ ${ }^{2}$ Milton Roy Mixing, 10 rue du Bois Gasseau, 77210 Samoreau, France \\ ${ }^{3}$ Air Liquide, CRCD, 1 chemin de la porte des Loges, BP 126, 78354 Jouy en Josas, France
}

\begin{abstract}
The use of oxygen enriched air is a common practice in high-temperature bioleaching tests $\left(>70^{\circ} \mathrm{C}\right)$ to overcome oxygen solubility limitation and reduced the energy costs of the process. Air is usually preferred in medium and low-temperature operations mainly for technical and economic constraints. Nevertheless, under high-sulfide loading conditions - high-grade metal sulfide concentrates and high solids concentration - the microbial and chemical demand for oxygen is significantly increased during the bioleaching process. If not satisfied, this high oxygen demand might limit the oxidation efficiency. Therefore it requires the injection of large amounts of air. Sparging with oxygen enriched gas instead of air may offer an interesting alternative process option to improve gas transfer in the bioleaching reactor and to provide an adequate oxygen supply in order to satisfy the oxygen demand. It might be useful to develop innovative alternative to the classical stirred tank reactor (STR) technology. However, the use of such conditions can lead to much higher dissolved oxygen (DO) concentrations than those encountered with air. Very few papers have been devoted to the study of the optimal range of DO concentrations for bioleaching processes. Most of them reported an inhibitory effect of DO concentrations above $5 \mathrm{ppm}$. The purpose of this study was to investigate the influence of DO on the bioleaching efficiency under oxygen-enriched atmosphere in $21 \mathrm{~L}$ stirred tank reactor at $42^{\circ} \mathrm{C}$. Bioleaching experiments were performed in continuous mode with sulfide-rich tailings wastes composed mainly of pyrite (51\%) and quartz using the "BRGM-KCC" bacterial consortia. The solid load was close to $20 \%(\mathrm{w} / \mathrm{w})$. Using various oxygen supply conditions (partial pressure, gas rate), the DO concentration in the reactor varied between 4 and $17 \mathrm{ppm}$. For a DO ranging from 4 to $13 \mathrm{ppm}$, a good bacterial oxidizing activity was observed and the sulfide dissolution efficiency increased with the DO concentration. It is assumed that this improvement of the bioleaching efficiency was linked to an increase of the oxygen transfer rate from the gas phase to the liquid phase rather than a direct effect of the DO level. When the DO concentration reached $17 \mathrm{ppm}$ a significant decrease of the microbial activity and consequently of the oxygen consumption was noticed. These results show that there is a critical value above which the DO concentration is detrimental to the activity of the bioleach microorganisms present in the "BRGM-KCC" consortia but this value is much higher than the one usually mentioned in the literature.
\end{abstract}

Key-words: bioleaching, oxygen, dissolved oxygen concentration, sulfide, bacteria monitoring, stirred tank reactor 


\section{1- INTRODUCTION}

Biohydrometallurgy is well established for the treatment of certain sulfide minerals, where iron and sulfur-oxidising bacteria are used for the leaching of low grade copper ores and the pretreatment of pyritic gold ores and concentrates. However part of the mining industry remains skeptical and reluctant to adopt biohydrometallurgical techniques as a reliable alternative option. Heap leaching is sometimes considered unsuitable due to space constraints, slow leaching kinetics and low recovery rate. The interest of using stirred tank reactor (STR) for the treatment of other minerals than refractory gold ores, such as the base metal sulfides, has already been demonstrated but some improvements are still needed to meet economic viability (d'Hugues et al., 2008; Spolaore et al., 2009 ; Kutschke et al. 2015). The main costs of bioleaching operations in STR are the costs associated with the leaching tanks and the gas mass transfer to the pulp. The main capital costs are the ones for the agitators and for the gas injection devices. The main operating costs are associated with the energy consumption required for slurry agitation and air compression, since air is usually used to provide oxygen in bioleaching operations (Rossi, 2001; Morin et d'Hugues, 2007; van Aswegen et al., 2007). The microorganisms involved in bioleaching processes get their energy through the oxidation of reduced sulfur compounds and iron (II). In these reactions oxygen is used as electron acceptor. In the case of pyrite bioleaching mechanisms involve the following oxidation reactions:

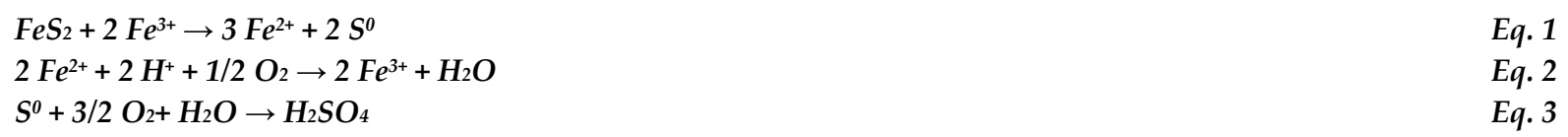

The reactions (2) and (3) are biologically catalyzed by acidophilic Fe- and S-oxidizing bacteria, whereas the reaction (1) occurs through chemical oxidation. The combination of the three reactions leads to the overall bioleaching reaction (Eq. 4) which shows that 3.5 mols of oxygen is required to oxidize $1 \mathrm{~mol}$ of pyrite.

$2 \mathrm{FeS}_{2}+4 \mathrm{H}^{+}+7 \mathrm{O}_{2}+2 \mathrm{H}_{2} \mathrm{O} \rightarrow 2 \mathrm{Fe}^{2+}+4 \mathrm{H}_{2} \mathrm{SO}_{4}$

Oxygen supply is thus a key issue, particularly in bioleaching processes with high-sulfide loading conditions where the microbial and chemical demand for oxygen is significantly increased. As a consequence, there is a need to inject large amounts of air which can be technically difficult and increases the costs of the process. Sparging with oxygen enriched gas instead of air may offer an interesting alternative process option to improve gas transfer and bioleaching efficiency by providing an adequate oxygen supply in order to satisfy high oxygen demand.

Gas mass transfer in bacterial leaching systems has been widely studied and is well documented (Bailey and Hansford, 1993a; Bailey and Hansford, 1994; Boon and Heijnen, 1998; Savic et al., 1998; Veglio et al., 1998). Transfer to liquid theory (illustrated schematically in Fig. 4) indicates that the $\mathrm{O}_{2}$ mass transfer rate, called Ro2 (quantity of oxygen transferred in liquid phase per unit of time) is given by:

$R_{o 2}=K_{L} a \times\left(C^{*}-C_{L}\right)$

Eq. 5

where: $\boldsymbol{R}_{02}$ is $\mathrm{O}_{2}$ transfer rate $\left(\mathrm{mol} \mathrm{m}^{-3} \mathrm{~s}^{-1}\right)$

$K_{L} \boldsymbol{a}$ is the volumetric oxygen mass transfer coefficient $\left(\mathrm{s}^{-1}\right)$

$C^{*}$ is the oxygen solubility in reactor conditions $\left(\mathrm{mol} \mathrm{m}^{-3}\right)$

$C_{L}$ is the oxygen concentration in the liquid phase $\left(\mathrm{mol} \mathrm{m}^{-3}\right)$

Several authors (Lui et al., 1987; Bailey and Hansford 1994; Jordan et al., 1995; Myerson, 1981; Bailey and Hansford, 1993b) have pointed out that the lack of adequate gas mass transfer is a rate limiting step in many bacterial leaching processes. The gas-liquid mass transfer rate depends on a number factors (Van Weert et al., 1995, d'Hugues et al., 1997, Boon and Heijnen, 1998) such as the reactor type, geometry and size, the gas-flow rate, sparger design and depth, the stirring speed, particle shape and size, pulp density and viscosity. However oxygen can become a limiting factor in bacterial leaching 
because of its low solubility: only $0.26 \mathrm{mM} \mathrm{O}_{2}(8.32 \mathrm{ppm})$ can dissolve per liter of water at $25^{\circ} \mathrm{C}$ in an air/water mixture. As mentioned by Witne and Phillips (2001), one way of increasing the solubility of oxygen in water or media solution is by increasing the driving force, i.e. raising the oxygen partial pressure in the gas stream supplied to the leach pulp. This mechanism is described by Henry's gas law which gives the solubility of oxygen in solution in relation to the oxygen partial pressure in the gas phase:

$C^{*}=\left(P^{\circ} / H\right)$

Eq. 6

where: $C^{*}$ is the oxygen concentration of the nutrient solution;

$P^{\circ}$ is the partial pressure of the gas in the gas phase;

$\boldsymbol{H}$ is Henry's constant, which is specific for the gas and the liquid phase.

Henry's gas law shows that the solubility of $\mathrm{O}_{2}$ in the leach pulp increases with increasing oxygen partial pressure in the gas stream. Higher $\mathrm{O}_{2}$ partial pressures could be attained when the bioreactor air or gas stream is enriched with added pure oxygen. This approach was used for the development of processes using high thermophiles culture by teams working on the development of STR processes for the bioleaching of chalcopyrite concentrates (Dew et al., 1999; d'Hugues et al, 2002). In these studies, oxygen was used instead of air because of the low solubility of $\mathrm{O}_{2}$ at high temperature. When working with mesophilic or moderately thermophilic microorganisms, they might be various interests of using $\mathrm{O}_{2}$ enriched air such as (i) to decrease the flow of gas stream injected in the pulp, reducing energy consumption linked to agitation and compression of air (ii) to improve gas transfer to satisfy higher oxygen demand associated with higher sulfide concentration. Using $\mathrm{O}_{2}$ enriched air is a promising alternative that might be useful to develop innovation to improve the classical STR technology. Air Liquide, Milton Roy Mixing and BRGM are currently testing an innovative bioleaching process using floating agitators to mix and to suspend solids in the solution as well as to inject gases in the pulp. This new concept enables to decrease the costs of bioleaching processes by operating in lagoons or ponds instead of using costly tanks, and at higher solid loading $(>20 \%)$ than in conventional stirred tank bioreactors. In these conditions of high solid load, the microbial and chemical demand for oxygen is significantly increased and air could be replaced by oxygen enriched gas to provide an adequate oxygen supply in order to satisfy the oxygen demand.

However the use of such conditions can lead to much higher dissolved oxygen (DO) concentrations than those encountered with air sparging. Very few papers have been devoted to the study of the optimal range of DO concentrations for bioleaching processes. However most of them reported an inhibitory effect of DO concentrations above 5 ppm (de Kock et al., 2004; Wang et al., 2015).

The purpose of this study was to investigate the influence of DO on the bioleaching efficiency of a mesophile to moderate thermophile consortium. The bioleaching tests were carried out under oxygenenriched atmosphere in a $21 \mathrm{~L}$ stirred tank reactor at $42^{\circ} \mathrm{C}$ in continuous mode with sulfide-rich tailings wastes composed mainly of pyrite (51\%) and quartz. The solid load was closed to $20 \%$ (w/w). The DO concentration in the reactor was varied between 4 and 18 ppm by increasing the gas flow rate. The influence of the DO level on the bioleaching efficiency was investigated through the monitoring of the sulfide leaching kinetics, the sulfide dissolution yield and the structure and the abundance of the microbial community.

\section{2- MATERIALS AND METHODS}

\section{Characterization of the sulfidic materials}

The experiments were performed using flotation tailings coming from a European copper mine. The mineral of economic interest in the ore body is chalcopyrite $\left(\mathrm{CuFeS}_{2}\right)$. At site, the ore is ground and valuable chalcopyrite is then separated from pyrite by flotation. Copper contained in the chalcopyrite is recovered by smelting whereas pyrite is discharged in tailings, from which the material used in this 
study was sampled. The tailings are mainly composed of pyrite $(51 \%)$ containing cobalt $(0.06 \%)$, copper $(0.19 \%)$ and gold $(1 \mathrm{~g} / \mathrm{t})$. This waste has been chosen as test materials for its high content of pyrite, which makes it particularly suitable for bioleaching.

\section{Bacterial culture and nutrients}

The experiments were carried out using the BRGM-KCC microbial consortium, which has already been fully described (d'Hugues et al., 2003). The predominant organisms in the culture are affiliated to Leptospirillum (L.) ferriphilum, Acidithiobacillus (At.) caldus and Sulfobacillus (S.) benefaciens. The culture used as an inoculum originated from BRGM stock culture, stored at $-80{ }^{\circ} \mathrm{C}$. The culture was subcultured several times in batch mode from $2 \mathrm{~mL}$ up to $21 \mathrm{~L}$ prior to the beginning of the test. The culture was grown in a nutrient medium called " $0 \mathrm{Km}$ ". This is a modified " $9 \mathrm{~K}$ " medium $(9 \mathrm{~K}$ without iron, " $\mathrm{m}$ " indicating modification of the basal salts) and it was optimised for bacterial growth on cobaltiferous pyrites. Its standard composition is the following: $\left(\mathrm{NH}_{4}\right)_{2} \mathrm{SO}_{4}, 3.70 \mathrm{~g} \mathrm{~L}^{-1} ; \mathrm{H}_{3} \mathrm{PO}_{4}, 0.80 \mathrm{~g} \mathrm{~L}^{-1}$; $\mathrm{MgSO}_{4} \bullet 7 \mathrm{H}_{2} \mathrm{O}, 0.52 \mathrm{~g} \mathrm{~L}^{-1} ; \mathrm{KOH}, 0.48 \mathrm{~g} \mathrm{~L}^{-1}$.

\section{Laboratory apparatus and experimental conditions}

Bioleaching tests were carried out in continuous mode using a $21 \mathrm{~L}$ (working capacity) laboratoryscale stirred tank. This tank is made from 316L stainless-steel and has a height/diameter ratio equal to 1. The top of the reactors was connected to a gas cooling system to prevent excessive evaporation. The bioleach slurry was mechanically stirred by a mixed (axial/radial) system (so-called BROGIM ${ }^{\circledR}-$ BRGM/MRM) mounted on a rotating shaft. The gas stream made of $\mathrm{N}_{2}, \mathrm{CO}_{2}$ and $\mathrm{O}_{2}$ supplied by Air Liquide gas cylinder was injected beneath the turbine at the bottom of the reactor via a stainless steel pipe. Gas mixture composition was controlled by valves and mass flow regulators for each gas. Gases went through a gas mixer before injection in the reactor. The feed was made up of a high density pulp flow $(40 \% \mathrm{wt} / \mathrm{wt}$ of sulfidic materials in water) and a concentrated nutrient medium flow. The two feed flows were pumped separately and injected into the tank in a ratio corresponding to the solids ratio $(20 \% \mathrm{w} / \mathrm{w})$ required for the feeding pulp. The combination of the two flows resulted in nutrient concentrations corresponding to $0 \mathrm{Km}$ medium. The residence time of the pulp in the tank was closed to 2.2 days. The $\mathrm{pH}$ was regulated between 1.2 and 1.5 by adding limestone slurry of $500 \mathrm{~g} \mathrm{~L}^{-1} \mathrm{CaCO}_{3}$. The standard temperature was $42^{\circ} \mathrm{C}$ and was maintained constant by circulating cold water through an internal stainless-steel coil.

Five conditions of gas flow rates and compositions were tested (Table 1). $\mathrm{CO}_{2}$ was maintained close to $1 \%$ during the whole assay. $\mathrm{O}_{2}$ partial pressure was first set to $56 \%$ and the gas flow rate was progressively increased from 50 to $500 \mathrm{NL} \mathrm{h}^{-1}$ (conditions 1 to 4 , see Table 1) in order to increase the concentration of dissolved oxygen in the liquid phase. In the last condition the gas flow rate was decreased to $250 \mathrm{NL} \mathrm{h}^{-1}$ and the oxygen partial pressure was set to $70 \%$. For each condition, the experiment was carried out for an average time of 20 days, which enabled to monitor the bioleaching test during several residence times and reach a steady state.

Table 1: Main operating conditions for the gas injection (the partial pressures are measured in the gas inlet after mixing of the $\mathrm{N}_{2}, \mathrm{O}_{2}$ and $\mathrm{CO}_{2}$ streams)

\begin{tabular}{|c|c|c|c|}
\hline & Gas flow rate & $\begin{array}{c}\mathbf{O}_{2} \text { partial } \\
\text { pressure }\end{array}$ & $\begin{array}{c}\mathrm{CO}_{2} \text { partial } \\
\text { pressure }\end{array}$ \\
\hline & $N L \mathrm{~h}^{-1}$ & $\%$ & $\%$ \\
\hline Condition 1 & 50 & 57.4 & 1.10 \\
\hline Condition 2 & 100 & 56.9 & 1.10 \\
\hline Condition 3 & 250 & 55.4 & 0.99 \\
\hline Condition 4 & 500 & 57.1 & 1.12 \\
\hline
\end{tabular}




\begin{tabular}{|l|l|l|l|}
\hline Condition 5 & 250 & 70 & 1.0 \\
\hline
\end{tabular}

\section{Analytical techniques}

\section{Daily monitoring}

Electrochemical potential, $\mathrm{pH}$ and dissolved oxygen (DO) were measured directly in the pulp. Samples of pulp were collected daily in the bioreactor and filtered (syringe filters in cellulose acetate, diameter $30 \mathrm{~mm}$, porosity $0.45 \mu \mathrm{m}$ ). Cobalt and total iron concentrations were measured by atomic absorption spectroscopy (Varian SpectrAA-300) in the filtered fraction. The $\mathrm{O}_{2}$ and $\mathrm{CO}_{2}$ concentrations in the inlet and outlet gas of the reactor were measured using a paramagnetic analyser and an infrared analyser (ADC 7000 - Analytical Development Company Ltd.) respectively. The gas balancing method was used to calculate the oxygen uptake rate (OUR). The oxygen transfer rate (OTR) and the OUR are linked by the following equation:

$$
O T R=O U R+\frac{d C_{O 2}}{d t}=\frac{Q_{O 2}^{i n}-Q_{O 2}^{o u t}}{V}
$$

where: $\mathrm{dCO} / \mathrm{d} t$ is the accumulation oxygen rate in the liquid phase,

$Q_{O} 2^{\text {in }}$ and $Q_{0}{ }^{\text {out }}$ are the oxygen gas flow at the bioreactor inlet and outlet,

$V$ the volume of the liquid phase in the bioreactor.

At steady state, when the DO concentration is constant, there is no accumulation of oxygen in the reactor and the OUR is equal to the OTR. Assuming that the nitrogen gas flow is the same at the inlet and outlet of the reactor (i.e. is not consumed neither transferred to the liquid phase), Eq. 7 becomes:

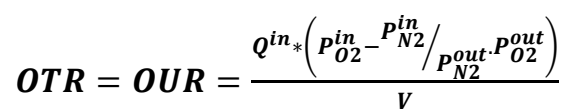
Eq. 8

where: $Q^{i n}$ is the gas flow rate at the inlet of the bioreactor,

$P_{\mathrm{N}^{2}}{ }^{\text {in }}$ and $P_{\mathrm{N} 2}{ }^{\text {out }}$ are the partial pressure of nitrogen in the gas at the inlet and outlet of the bioreactor.

\section{Analysis of the solid fractions and mass balances}

When the bioleaching reactor was operating at steady state, samples were collected from the overflowing pulp at the exit of the reactor and from the initial pulp feed. The samples of pulp were first filtered with a Büchner funnel to separate liquid and solid phases. The filtered solid material was then rinsed with a sulfuric acid solution at $\mathrm{pH} 1.8$ and dried. Representative aliquots of the dried materials $(<80 \mu \mathrm{m})$ were analysed for metal contents (namely $\mathrm{Fe}, \mathrm{Co}, \mathrm{Cu})$, total carbon and sulfur speciation. Major and trace metal contents were determined by ICP-AES (Inductively Coupled Plasma-Atomic Emission Spectrometry) after oxidizing digestion according to protocols dedicated to ore analysis (degradation of all sulfides). Total carbon and total sulfur were determined using a Leco analyzer: i.e. non-dispersive infrared analysis of $\mathrm{CO}_{2}$ and $\mathrm{SO}_{2}$ gas respectively, after heating and passing of an oxygen stream. The same technique was used for sulfide $\left(\mathrm{S}^{2-}\right)$ determination, once the sample has been leached in warm sodium carbonate solution to convert the metal sulfate into insoluble carbonates and soluble sulfate. Sulfate was determined by gravimetry after the sample being leached at boiling temperature with a sodium carbonate solution, ferric ion reduced to ferrous iron by the addition of hydroxylamine hydrochloride, and the filtrate being precipitated with barium chloride. The analytical data were then used to calculate the mass balance of the operation and to assess the bioleaching performances (sulfide oxidation rates and yields).

\section{Bacterial community monitoring}

Homogeneous $2 \mathrm{~mL}$ pulp samples were taken at the end of the steady state of each of the five operating conditions. After centrifugation, the pellet was washed in Tris buffer (100 mM, pH 8) until acidity was neutralized, and genomic DNAs were extracted with the FastDNA Spin Kit for Soil and manufacturer's protocol (MP Biomedicals), except for a speed of 5 for $30 \mathrm{~s}$ for mechanical lyses. DNA 
was also extracted with the same procedure from filtrate $(2 \mathrm{~mL})$ and solids (about $0.7 \mathrm{~g}$ ) obtained after filtration of homogeneous pulp, in order to characterize bacteria located in the liquid phase or associated with the solids. The abundance of each inoculated strains, i.e. L. ferriphilum, At. caldus, and S. benefaciens, was determined by measuring abundance of their $16 \mathrm{~S}$ rRNA gene using species-specific real-time quantitative PCR (qPCR) performed with the newly developed assays described by Hedrich et al. (2016). Results were expressed as numbers of gene copies per $\mathrm{mL}$ of bioleaching pulp.

\section{3- RESULTS}

\section{1- Influence of the dissolved oxygen on the dissolution rate and the OUR}

The oxygen partial pressures analyzed in the gas inlet and outlet for the five tested conditions and the corresponding oxygen solubility calculated using Henry's law (Eq. 6) are gathered in Table 2. This table presents also the DO concentration measured in the reactor. The gas injection conditions selected enabled to test a wide DO concentration range from $4.7 \mathrm{ppm}$ to $17.7 \mathrm{ppm}$.

Table 2: Oxygen concentration in the gas phase and in the liquid phase in continuous pyrite bioleaching experiments $\left(\mathrm{O}_{2}\right.$ partial pressure measured in the gas inlet $\left(\mathrm{P}_{2}\right.$ in) and outlet $\left(\mathrm{P}_{2}\right.$ out) and corresponding $\mathrm{O}_{2}$ solubility calculated using Henry's law; DO concentration measured in the reactor)

\begin{tabular}{|l||c|c||c|c||c|}
\hline & Po2 in & $\begin{array}{c}\text { O2 solubility* } \\
\text { corresponding } \\
\text { to Po2 in }\end{array}$ & Po2 out & $\begin{array}{c}\text { O2 }_{2} \text { solubility* } \\
\text { corresponding } \\
\text { to Po2 out }\end{array}$ & $\begin{array}{c}\text { measured DO } \\
\text { concentration }\end{array}$ \\
\hline Condition 1 & 57.4 & 17.6 & 41.1 & 12.6 & $p p m$ \\
\hline Condition 2 & 56.9 & 17.5 & 48.3 & 14.8 & 5.7 \\
\hline Condition 3 & 55.4 & 17.0 & 51.7 & 15.9 & 9.5 \\
\hline Condition 4 & 57.1 & 17.5 & 55.2 & 16.9 & 12.9 \\
\hline Condition 5 & 70 & 21.8 & 69 & 21.3 & 17.7 \\
\hline
\end{tabular}

The variation in OUR and pyrite dissolution rate for the five tested conditions is shown in Fig. 1. Both increased when the DO concentration is increased from $4.7 \mathrm{ppm}$ to $12.9 \mathrm{ppm}$, which corresponds to the conditions 1 to 4 . OUR values are close to the values of pyrite dissolution rate as expected from Eq. 4 which shows that the bioleaching of $1 \mathrm{~kg}$ of pyrite consumes $1 \mathrm{~kg}$ of oxygen.

For the condition 5 where the DO concentration reached $17.7 \mathrm{ppm}$ a sharp decrease of the pyrite dissolution rate was observed. In that case it was not possible to calculate the corresponding OUR because of the lack of precision in the analysis of the gas composition. 


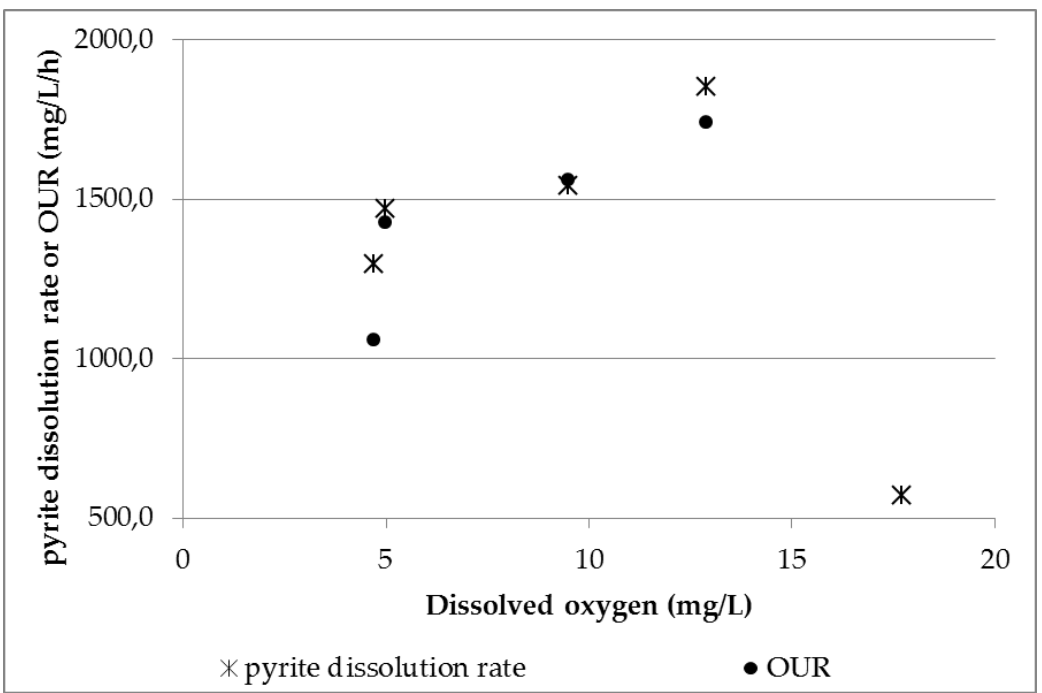

Figure1: Pyrite dissolution rate and OUR vs. DO concentration in continuous pyrite bioleaching experiments

\section{2- Influence of the dissolved oxygen on the dissolution yields}

In table 3 are reported the sulfide dissolution yields obtained for each tested conditions and the corresponding residence time. The slight variation in residence time can be explained by variation in the pumps flows for the calcite as it varies with the leaching efficiency and the corresponding production of sulfuric acid (see Eq. 4). It explains why the residence time is not constant especially for the conditions 1 and 5 for which the oxidizing activity was lower (as shown by the lower values of

Table 3: Residence time and sulfide dissolution yield

\begin{tabular}{|c|c|c|c|}
\hline & $\begin{array}{c}\text { measured DO } \\
\text { concentration }\end{array}$ & Residence time & $\begin{array}{c}\text { Sulfide } \\
\text { dissolution yield }\end{array}$ \\
\hline & $p p m$ & $d$ & $\%$ \\
\hline Condition 1 & 4.7 & 2.5 & $63 \%$ \\
\hline Condition 2 & 5.0 & 2.2 & $56 \%$ \\
\hline Condition 3 & 9.5 & 2.2 & $61 \%$ \\
\hline Condition 4 & 12.9 & 2.2 & $77 \%$ \\
\hline Condition 5 & 17.7 & 2.4 & $29 \%$ \\
\hline
\end{tabular}

When looking at the conditions 2, 3 and 4 for which the residence time is the same, the sulfide dissolution yield increased with the DO concentration. For the condition 4 the sulfide dissolution yield reached $77 \%$ for a DO concentration of $12.9 \mathrm{ppm}$. These results as well as the corresponding values of OUR and pyrite dissolution rates show (i) that the oxidizing activity in the bioleaching reactor is high from 5 to $12.9 \mathrm{ppm}$ DO concentration and (ii) this activity is enhanced when the DO concentration increases.

For the condition 1 the sulfide dissolution yield is higher than for the conditions 2 and 3 . But it is likely that this result is linked to the higher residence time in the reactor rather than to an effect of the DO considering the OUR and the pyrite dissolution rate which are both lower for the condition 1 than for the conditions 2 and 3. For the condition 5 the sulfide dissolution yield drops to $29 \%$ despite the 
higher residence time. This result is in accordance with the decrease of pyrite dissolution rate observed for this condition and seems to confirm the appearance of an inhibitory effect of the DO concentration on the biological activity when the DO becomes too high.

\section{3- Influence of the dissolved oxygen on the microbial community (abundance and structure)}

The bacterial community composition shows that the strains present in the bioleach pulp were the same as the three main strains which make up the BRGM-KCC consortium used to inoculate the bioreactors. They are all found in the five tested condition, L. ferriphilum being dominant and accounting for up to $80 \%$ of the total community (Fig 2).

The influence of DO on the biomass was studied, using 16S rRNA gene abundances as a measure of total biomass as well as strain specific abundances. The total biomass was negatively affected by an increase of DO, as shown by the decrease especially marked at a DO of $17.7 \mathrm{ppm}$ where about one log of gene copy numbers was lost (Fig. 2). The strains composing the community followed the same trend. Especially, At. caldus abundance, although high at low DO (4.7 and 5 ppm), showed a regular diminution all along the experiment as well as the sharper decrease $(1 \log )$ as soon as DO increased from 5 to $9.5 \mathrm{ppm}$. Interestingly, At. caldus represented the large majority of planktonic bacteria recovered from the liquid compartment (see Fig. 3) and accounted for more than $96 \%$ of the total planktonic community at DO of 4.7 and 5 ppm, respectively. At 17.7 ppm however, the biomass of all strains had decreased, and L. ferriphilum and S. benefaciens appeared to be only slightly less affected (1.9 $\log$ between conditions 1 and 5) than At. caldus (2.3 log).

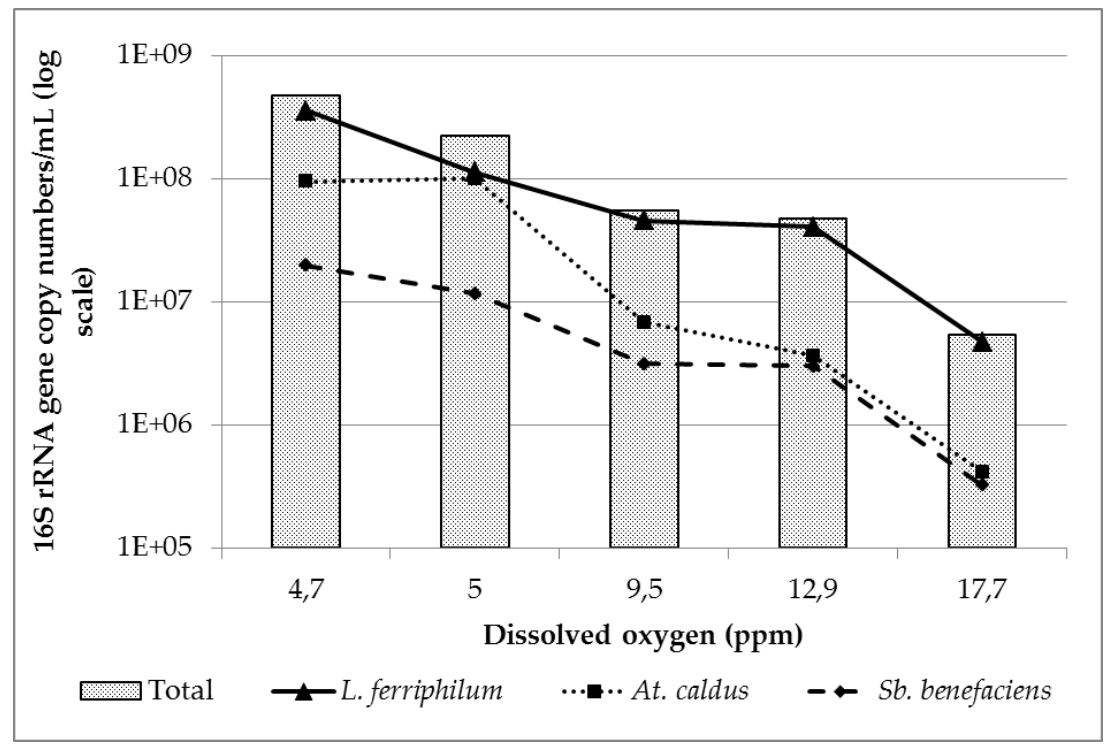

Figure 2: Influence of DO concentration on the microbial community structure and the quantity of biomass present in the reactor (assessed using the number of 16S rRNA gene copy) 


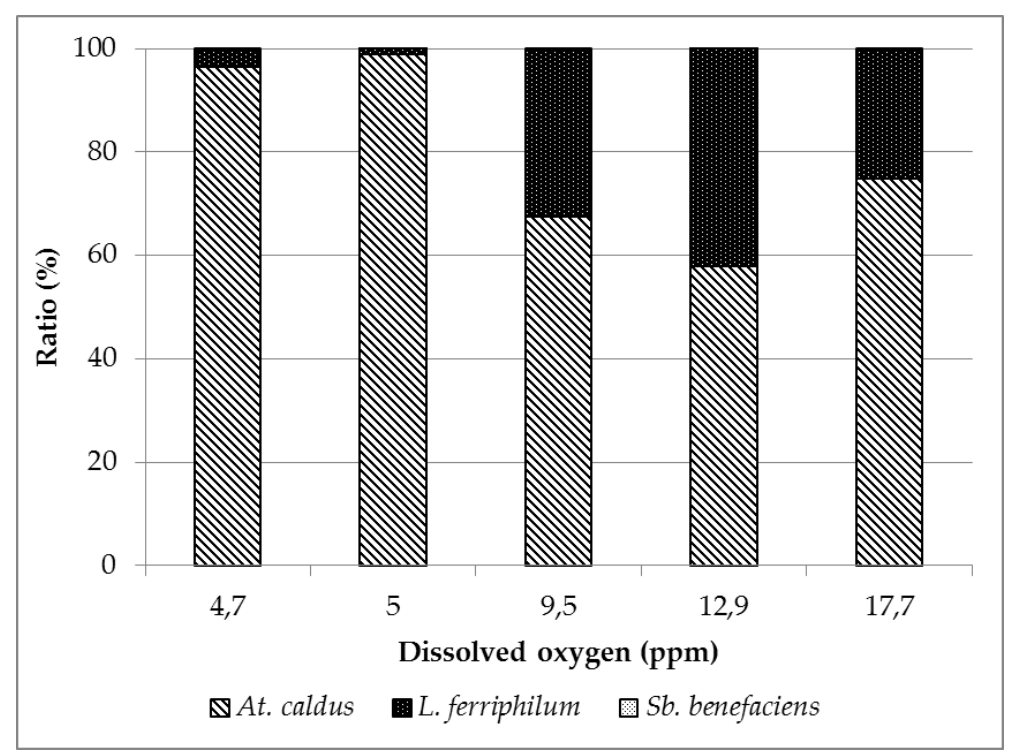

Figure 3: Structure of the microbial community in the liquid compartment

\section{DISCUSSION}

It is likely that a dissolved oxygen concentration between 13 and $17 \mathrm{ppm}$ is critical for the bioleaching efficiency. Below this critical value bioleaching efficiency increases with the DO concentration. It is assumed that this improvement of the bioleaching efficiency is linked to an increase of the oxygen transfer rate from the gas phase to the liquid phase rather than a direct effect of the DO level. This hypothesis is partially confirmed by the increase of the oxygen uptake rate which is equal to the oxygen transfer rate in steady state mode. Above this critical value the DO concentration starts to be detrimental to the microbial activity and a sharp decrease of bioleaching efficiency (associated with a significant decrease of the bacterial population) is observed. This critical value is difficult to determine since the DO concentration depends on the rate of oxygen transferred from the gas phase to the liquid phase and from the oxygen consumed by the bio-oxidation. As soon as the DO concentration is above this critical value, the microbial activity decreases as well as the oxygen consumption, which entails an increase of the DO concentration.

The DO level which affects negatively the efficiency of bioleaching with the KCC consortium is quite different from those previously mentioned in the literature which reports an inhibitory effect for much lower DO levels. Especially this study can be compared to the results published recently by Wang et al. (2015) which studied the effect of dissolved oxygen on bioleaching using a sulfidic material and a microbial community similar to the ones used in this study. The optimum activity of the microbial population was obtained at $3.75 \mathrm{ppm}$ concentration of DO. Above and below this value the OUR, the oxidation rate and the oxidation ratio decreased. It must be noted that Wang et al. carried out their experiments at $10 \%$ solids and in batch mode. The maximum OUR measured was closed to $160 \mathrm{mg} \mathrm{L}$ ${ }^{1} \mathrm{~h}^{-1}$, which is more than ten times lower than the maximum OUR measured in this study. The microbial oxidizing activity was thus much lower. In the absence of data regarding the gas flow rate and its composition (especially the partial pressure of oxygen) it is difficult to explain the discrepancies observed between both studies, but it can be assumed that the influence of DO concentration on the bacterial activity is very dependent on the other operating conditions such as the solid concentration and the culture mode. It might also be bacterial strain dependent.

The increase of DO concentration has also a noticeable influence on the biomass which progressively decreases when the DO concentration increases. Below $13 \mathrm{ppm}$ At. caldus seems to be the most affected by the increase of DO concentration. This might suggest that At. caldus is less tolerant to high DO concentrations than the other strains of the KCC consortium. Nevertheless other factors must also be 
considered and especially the fact that At. caldus is the most abundant strain in the liquid phase compared to L. ferriphilum and S. benefaciens which are mainly located on the particles. Because of the presence of these bacteria on the solid phase it can be assumed that the oxidation of FeII and sulfur occur also at the surface of the pyrite particles. Oxygen is thus consumed at the liquid/solid interface and its transfer in the liquid/solid boundary layer is governed by the same theory as the one presented in the introduction:

$R_{02}=K_{s} . a_{s} .\left(C_{L}-C_{S}\right)$

Eq. 7

where: $\mathrm{Ro}_{2}$ is $\mathrm{O}_{2}$ mass transfer rate $\left(\mathrm{mol} \mathrm{m}^{-3} \mathrm{~s}^{-1}\right)$

$K_{s}$ is the mass transfer coefficient $\left(\mathrm{m} \mathrm{s}^{-1}\right)$

as is the solid specific area $\left(\mathrm{m}^{-1}\right)$

$C_{L}$ is the oxygen concentration in the liquid phase $\left(\mathrm{mol} \mathrm{m}^{-3}\right)$

$C_{S}$ is the oxygen concentration at the solid surface $\left(\mathrm{mol} \mathrm{m}^{-3}\right)$

This phenomenon is illustrated in Fig. 4 and shows that the oxygen concentration in the liquid phase is higher than the one at the surface of the particles. The transfer rate being closely linked to the oxygen consumption in the system the difference (also called "driving force") is higher when the oxygen consumption rate increases. Planktonic cells are thus submitted to higher DO concentrations than the cells attached to the particles, which might explain that At. caldus abundance decreases more quickly than L. ferriphilum and S. benefaciens.

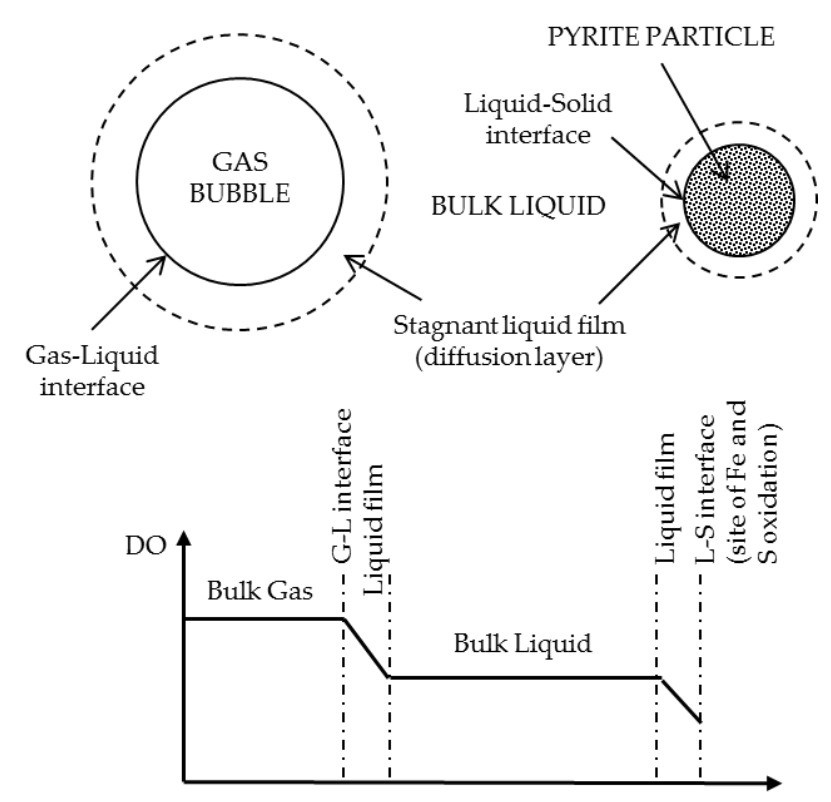

Figure 4: Schematic description of oxygen transfer and oxygen concentration profile in a triphasic media with reactions consuming oxygen at the solid surface

The level of detrimental effect may also be linked to the capacity of a cell to handle high DO concentration. The toxicity of the oxygen towards the bacteria involved in bioleaching might be linked to the formation of reactive oxygen species (ROS) by a mechanism involving Fenton and Haber-Weiss reactions. By switching oxidation states metal ions further activate species like hydrogen peroxide $\left(\mathrm{H}_{2} \mathrm{O}_{2}\right)$ and superoxide $\left(\mathrm{O}_{2}{ }^{\circ}\right)$ to the highly reactive hydroxyl radical ('OH) (Imlay, 2008). ROS are known to have deleterious effects on cells through a mechanism called oxidative stress (Halliwell 2007). Several authors (Borda et al., 2003; Cohn et al., 2006; Schoonen et al., 2006; Schoonen et al., 2010) have shown that the oxidation of pyrite in solutions containing dissolved oxygen leads to the formation of ROS through several mechanisms that are synthetized in Fig. 5. As can be seen the ROS 
concentration in the leaching solution would increase with the DO concentration. Recently, evaluations in tank reactors have also shown the negative influence of ROS generation (due to fine grinding of pyrite) on bioleaching (Jones et al., 2011), suggesting the direct effect of external ROS generation on bioleaching organisms. Bioleaching bacteria harbor genetic systems for the defense against oxidative stress by the production of various proteins involved in anti-oxidative protection and biomolecules repair mechanisms (Cardenas et al., 2012). If there is evidence that Leptospirillum, Sulfobacillus and Acidithiobacillus strains possess such systems, the mechanisms are not fully understood yet and their efficiencies depending on genus or strain during bioleaching are not known.

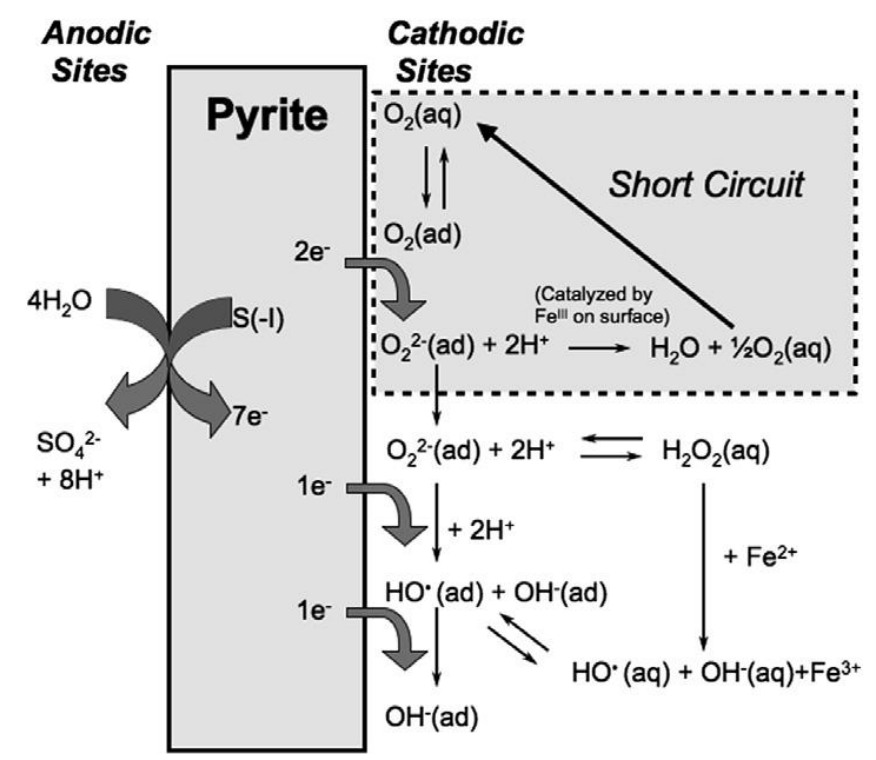

Figure 5: ROS formation mechanisms at pyrite surface (Schoonen et al. 2010)

\section{CONCLUSION}

The BRGM-KCC microbial consortium can tolerate DO levels up to $13 \mathrm{ppm}$, and probably higher level with a critical limit between 13 and $17.7 \mathrm{ppm}$, during continuous bioleaching and still maintain a high bioleaching activity. This value is much higher than the maximal DO levels reported in previous papers and is also higher than the solubility of oxygen in an air/water mixture $\left(8.3 \mathrm{ppm}\right.$ at $25^{\circ} \mathrm{C}, 6$ ppm at $40^{\circ} \mathrm{C}$ ). The bioleaching efficiency (oxidation rate and dissolution yield) increases with the increase of the oxygen supply (and oxygen transfer) up to a DO concentration of $13 \mathrm{ppm}$. However the microbial activity and consequently the oxygen consumption significantly decreased at DO concentration of $17 \mathrm{ppm}$. These results confirm the applicability of using oxygen enriched gas instead of air to efficiently supply oxygen in bioleaching reactors without inhibitory effect on the microbial oxidizing activity. However the oxygen partial pressure and the gas flow must be carefully adapted to the oxygen requirements of the system to avoid too high DO concentrations in the bioreactors.

Acknowledgments: This work is part of the collaborative bilateral research project Ecometals cofunded by the German Federal Ministry of Education and Research (BMBF under the grant ID 033RF001) and the French National Research Agency (ANR-13-RMNP-0006). The authors thank M. Djemil, H. Tris for their technical involvement during the pilot operation.

\section{REFERENCES}


Bailey, A. D., and Hansford, G. S., (1993a). Factors affecting bio-oxidation of sulfide minerals at high concentrations of solids: a review. Biotechnology and Bioengineering, 42(10), 1164-1174.

Bailey, A. D., and Hansford, G. S., (1993b). A fluidised bed reactor as a tool for the investigation of oxygen availability on the bio-oxidation rate of sulphide minerals at high solids concentrations. Minerals Engineering, 6(4), 387-396.

Bailey, A. D., and Hansford, G. S., (1994). Oxygen mass transfer limitation of batch bio-oxidation at high solids concentration. Minerals Engineering, 7(2--3), 293-303.

Boon, M., and Heijnen, J. J., (1998). Gas-liquid mass transfer phenomena in bio-oxidation experiments of sulphide minerals. A critical review of literature data, Hydrometallury, 48, 187-204.

Borda M. J., Elsetinow A. R., Strongin D. R. and Schoonen M. A. (2003) A mechanism for the production of hydroxyl radical at surface defect sites on pyrite. Geochimica et Cosmochimica Acta 67, 935-939

Cárdenas, J. P., Moya, F., Covarrubias, M., Shmaryahu, A., Levicá, G., Holmes, D. S., and Quatrini, R. (2012) Comparative genomics of the oxidative stress response in bioleaching microorganisms. Hydrometallurgy, 127-128, 162-167.

Cohn A.C., Mueller S., Wimmer E., Leifer N., Greenbaum S., Strongin D.R. and Schoonen M.A.A (2006) Pyrite-induced hydroxyl radical formation and its effect on nucleic acids. Geochemical Transactions $7,3$.

d'Hugues, P., Cezac, P., Cabral, T., Battaglia, F., Truong-meyer, X. M., and Morin, D., (1997). Bioleaching of a cobaltiferous pyrite: A continuous laboratory-scale study at high solids concentration. Minerals Engineering, 10(55), 507-527.

d'Hugues, P., Foucher, S., Galle-Cavalloni, P., Morin, D., (2002). Continuous bioleaching of chalcopyrite using a novel extremely thermophilic mixed culture. International Journal of Mineral Processing, 66, 107-119.

d'Hugues, P., Battaglia-Brunet, F., Clarens, M., Morin, D. (2003). Microbial diversity of various metalsulfides bioleaching cultures grown under different operating conditions using 16S-rDNA analysis. In: Tsezos, M., Remoudaki, E., Hatzikioseyian, A. (Eds.), International Biohydrometallurgy Symposium IBS 2003. Hellas, Athens, 1313-1324

d'Hugues, P., Norris, P.R., Hallberg, K.B., Sanchez, F., Langwaldt, J., Grotowski, A., Chmielewski, T., Groudev, S. (2008). Bioshale FP6 European project: Exploiting black shale ores using biotechnologies? Minerals Engineering, 21, 111-120.

de Kock, S.H., Barnard, P., du Plessis, C.A., (2004). Oxygen and carbon dioxide kinetic challenges for thermophilic mineral bioleaching processes. Biochemical Society Transactions, 32, 273-275

Dew, D.W., Van Buuren, C., Mc Ewan, K., Bowker, C., (1999). Bioleaching of base metal sulphide concentrates: a comparison of mesophile and thermophile bacterial cultures. In: Amils, R., Ballester, A. (Eds.), Process Metallurgy 9A, Biohydrometallurgy and Environment Toward the Mining of the 21st Century. IBS' 99 Symposium. Elsevier, Amsterdam, The Netherlands, pp. $229-238$.

Halliwell, B., 2007. Biochemistry of oxidative stress. Biochemical Society Transactions 35 (5), 11471150.

Imlay, J.A., 2008. Cellular defenses against superoxide and hydrogen peroxide. Annual Review of Biochemistry 77, 755-776.

Hedrich, S., Guézennec, A.-G.G., Charron, M., Schippers, A. and Joulian, C. (2016) Development of molecular assays to efficiently monitor and quantify microbial species during bioleaching of copper-rich ores. Biohydrometallurgy'16, Falmouth (UK), June 20-22, 2016. 
Jones G.C., Corin K.C., van Hille R.P., Harrison S.T.L. (2011) The generation of toxic reactive oxygen species (ROS) from mechanically activated sulphide concentrates and its effect on thermophilic bioleaching. Minerals Engineering 24, 1198-1208

Jordan, M.A., McGinness, S. and Phillips, C.V. (1995). Acidophilic bacteria, their potential mining and environmental applications, Minerals Engineering, 9(2), 169-181.

Kutschke S., Guézennec A.G., Hedrich S., Schippers A., Borg G., Kamradt A., Gouin J., Giebner F., Schopf S., Schlömann M., Rahfeld A., Gutzmer J., P. D'Hugues, Pollmann K., Dirlich S., Bodénan F. (2015) Bioleaching of Kupferschiefer blackshale - A review including perspectives of the Ecometals project. Minerals Engineering 75, 116-125

Lui, M. S., Brvaaion, R.M.R., and Ducan., (1987). Oxygen transfer to Thiobacillus cultures, in: Biohydrometallurgy, Proceedings of International Symposium, Warwick, P.R. Norris and D.P. Kelly (eds.), Science \& Technology Letters, Kew, Surrey, 375.

Myerson, A.S., (1981), Oxygen mass transfer requirements during the growth of Thiobacillus ferrooxidans on iron pyrite. Biotechnology and Bioengineering, 23, 1413.

Rossi, G., The design of bioreactors. Hydrometallurgy, 59, 217-231.

Savic, D. S., Veljkovic, V. B., Lazic, M. L., Vrvic, M. M., and Vucetic, J. I., (1998). Effect of the oxygen transfer rate on ferrous iron oxidation by ThiobaciUus ferrooxidans., Enzyme Microbiological Technology, 23, 427--431.

Schoonen, M.A.A, Cohn, C.A, Roemer, E., Laffers, R., Simon, S.R., O'Riordan,T., , (2006). MineralInduced Formation of Reactive Oxygen Species. Reviews in Mineralogy \& Geochemistry, 64, 179221.

Schoonen, M.A.A, Harrington, A.D., Laffers, R., Strongin, D.R., (2010). Role of hydrogen peroxide and hydroxyl radical in pyrite oxidation by molecular oxygen. Geochimica et Cosmochimica Acta, 74, 4971-4987

Spolaore, P., Joulian, C., Gouin, J., Morin, D., \& d'Hugues, P. (2009). Bioleaching of an organic-rich polymetallic concentrate using stirred-tank technology. Hydrometallurgy, 99, 137-143.

Van Weert, G., Van Der Werff, D. and Derksen, J. J., (1995). Transfer of oxygen from air to mineral slurries in a Rushton turbine agitated tank. Minerals Engineering, 8(10), 1109-1124.

Veglio, F., Beolchini, F., and Ubaldini, S., (1998). Empirical models for oxygen mass transfer: a comparison between shake flask and lab-scale fermentor and application to manganiferous ore bioleaching, Process Biochemistry, 33(4), 367-376.

Wang, H., Zhang, X., Zhu, M, Tan, W., (2015). Effects of dissolved oxygen and carbon dioxide under oxygen-rich conditions on the biooxidation process of refractory gold concentrate and the microbial community. Minerals Engineering, 80, 33-44.

Witne, J.Y. and Phillips, C.V., (2001). Bioleaching of Ok Tedi copper concentrate in oxygen- and carbon dioxide enriched air. Minerals Engineering, 14 (1), 25-48.

Morin, D. and d'Hugues, P., Bioleaching of a cobalt-containing pyrite in stirred reactors: a case study from laboratory scale to industrial application. In Biomining, ed. D.E. Rawlings and D.B. Johnson. Springer-Verlag, Berlin Heidelberg, 2007, pp 35-56.

Van Aswegen, P.C., Van Niekerk, J. and Olivier, W., The BIOX process for the treatment of refractory gold concentrates. In Biomining, ed. D.E. Rawlings and D.B. Johnson. Springer-Verlag, Berlin Heidelberg, 2007, pp1-34. 